\title{
Theoretical tissue compartment inert gas pressures during a deep dive with and without deep decompression stops: a case analysis
}

\author{
Peter Buzzacott ${ }^{1,2}$, Virginie Papadopoulou ${ }^{3,4}$, Adrian Baddeley ${ }^{5,6}$, Nadan M. Petri ${ }^{7}$, Folke Lind ${ }^{8,9}$ \\ ${ }^{1}$ Université de Bretagne Occidentale, Brest, France \\ ${ }^{2}$ School of Sports Science, Exercise and Health, University of Western Australia, Perth, Australia \\ ${ }^{3}$ Department of Bioengineering, Imperial College London, London, United Kingdom \\ ${ }^{4}$ Haute Ecole Paul Henri Spaak, Brussels, Belgium \\ ${ }^{5}$ School of Earth and Environment, University of Western Australia \\ ${ }^{5}$ University of Aarhus, Denmark \\ ${ }^{6}$ Science Fellow at CSIRO Computational Informatics, Perth, Australia \\ ${ }^{7}$ University of Split School of Medicine, Split, Croatia \\ ${ }^{8}$ Hyperbaric Medicine at the Department of Anaesthesiology, Surgical Services and Intensive Care, \\ Karolinska University Hospital, Stockholm, Sweden \\ ${ }^{9}$ Environmental and Respiratory Physiology at the Department of Physiology \\ at the Karolinska Institutet, Stockholm, Sweden
}

\begin{abstract}
Background: Deep decompression stops are increasingly common in recreational technical diving. Concerns exist that they shift decompression stress back into slower tissues. A diver recorded an exceptional exposure dive, with deeps stops, on a commercially available dive computer.

Material and methods: Using the R package SCUBA tissue inert gas pressures in 17 BühImann (ZH-L16A) compartments were estimated from the dive computer recorded profile. The RGBM dive plan generated by the diver's software was similarly interrogated, as was a third profile with reduced deep stops generated using the VPM-B/E model.

Results: In this dive the combination of 5 gas switches appeared to ameliorate the effect of deep stops from $76 \mathrm{~m}$ depth.

Conclusions: A higher-than-anticipated inert gas content in a decompression mixture, coupled with climbing 200 stairs post-decompression, appear possible risk factors for decompression sickness. Nonetheless, the physiological effect of deep decompression stops during exceptional exposure, even when diving with gas switches, remains urgently to be determined to improve safe decompression following exceptional exposures. Until algorithms utilising deep decompression stops are validated with human data, dive profiles incorporating deep decompression stops should be considered experimental.
\end{abstract}

(Int Marit Health 2015; 66, 1: 36-42)

Key words: diving computer, decompression, deep diving, gas solubility, models, technical diving

"Diving in general is fraught with risk, and decompression diving adds significantly more risk. Deep diving utilizing multiple gasses, including Helium, is about as risky as it gets."
Advice that followed the alternate dive plan generated by V-planner

(HHS Software Corp., Kingston, ON, Canada) 


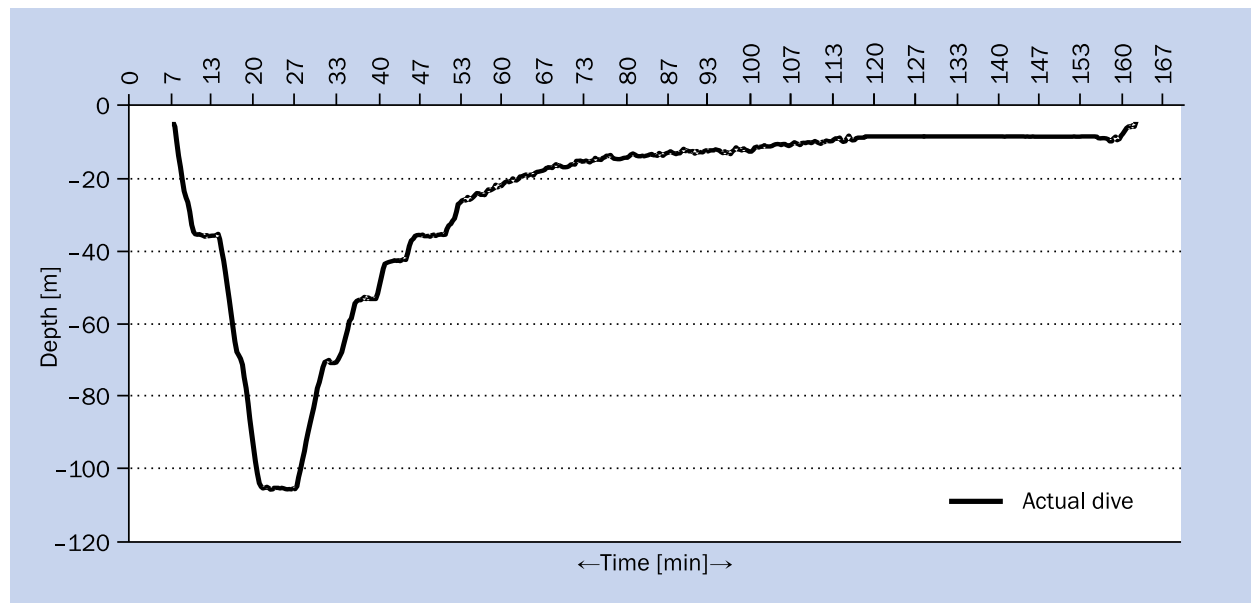

Figure 1. The dive profile from the diver's personal dive computer

\section{INTRODUCTION}

Recreational diving beyond traditional "no stop" time and depth limits (recreational technical diving), has undergone explosive growth in recent years [1, 2]. Empirically-derived "Haldanean" decompression models such as those developed by Bühlmann are being replaced in personal dive computers and in desktop decompression planning software by a new generation of "bubble models" [3]. To our knowledge, the algorithms these models use have not been validated either with human trials or probabilistically through fitting to existing human trials data. A characteristic of bubble models is that an ascending diver's first prescribed decompression stop is usually considerably deeper than if the same dive were planned with a Haldanean model $[3,4]$. During exceptionally deep dives deeper stops may shift decompression stress towards slower theoretical compartments and result in surfacing with higher compartment pressures than Haldanean models allow [2, 4]. Doolette and Mitchell [4] noted that gas switching to elevated partial pressures of oxygen may ameliorate this potential hazard. Limited available evidence appears to support a more cautious approach than some current dive computer manufacturers may be observing. A study using a swine model found that, compared with a classical Bühlmann profile, deep stops after shallow decompression dives (30 $\mathrm{msw}$ for $70 \mathrm{~min}$ ) reduced vascular bubbles but after diving to $65 \mathrm{msw}$ for $20 \mathrm{~min}$ dramatically increased vascular bubbles [5]. After diving to $51 \mathrm{msw}$ for $30 \mathrm{~min}$, United States Navy divers suffered both higher incidence of decompression sickness (DCS) and higher grade of observed venous gas emboli when making deep stops during decompression ( $n=198$ dives) compared with only shallower stops $(n=192$ dives) [6]. Following an exceptional exposure, a diver known to the lead author asked for the analysis of his recorded dive profile to identify if there were any obvious likely contributing factors.

The aim of this study was to assess to what degree, if any, the inclusion of deep stops generated by bubble-model software re-distributed estimated tissue inert gas pressures between faster and slower compartments in this single exceptional exposure. Using compartment pressure estimation software, this study compares estimated tissue pressures from the actual dive with estimates from two dive plans generated using desktop software; the diver's original Reduced Gradient Bubble Model (RGBM) plan with deep stops and a second bubble-model derived plan with reduced deep stops.

\section{MATERIALS AND METHODS}

A 33-year-old, experienced, fit, male technical diver with no previous history of DCS undertook a deep cave dive in $4^{\circ} \mathrm{C}$ water for the purpose of exploration. Five years prior to this dive he had been screened for atrial septal defect with colour flow Doppler echocardiography but found to have only a small high muscular ventricular septum defect with a pure left to right shunt and a pressure fall of $80 \mathrm{~mm} \mathrm{Hg}$ that had been considered neither of clinical significance nor of increased diving-related risk. He dived in a dry suit using open circuit SCUBA to 110 metres' fresh water (mfw) for 7 min (total descent and time at maximum depth 23 min) with a bottom gas mixture containing 8\% oxygen and $70 \%$ helium, followed by $147 \mathrm{~min}$ of decompression on 4 different gas mixtures (trimix 16/49, 30/28, 39/14 and $100 \%$ lastly). The oxygen was breathed in a dry habitat at $4.5 \mathrm{mfw}$ (Fig. 1), with wooden benches for supine decompression inside a dry, rock air bell. The dive was planned with Dive Manager 4 dive planning software (Suunto Oy, Vantaa, Finland) with "0" conservatism setting. Actual gas 
Table 1. Planned and actual gas blends $\left(\% \mathrm{~N}_{2}, \mathrm{He}, \mathrm{O}_{2}\right)$ with time [min] of use and depth [m] range

\begin{tabular}{|c|c|c|c|c|c|c|}
\hline Profile & Descent & Bottom & Deco1 & Deco2 & Deco3 & Deco 4 \\
\hline Planned dive ${ }^{a}$ & $40,30,30$ & $22,70,8$ & $34,50,16$ & $40,30,30$ & $40,10,50$ & $0,0,100$ \\
\hline From-to [min] & $0-5$ & $5-30$ & $30-46$ & $46-55$ & 55-104 & $104-145$ \\
\hline Depth range [m] & $0-34$ & $34-73$ & $73-35$ & $35-21$ & $61-6$ & $6-0$ \\
\hline Actual dive $^{a}$ & $42,28,30$ & $18,74,8$ & $35,49,16$ & $42,28,30$ & $47,14,39$ & $0,0,100$ \\
\hline From-to [min] & $0-6$ & $6-29$ & $29-46$ & $46-50$ & $50-113$ & $113-170$ \\
\hline Depth range [m] & $0-34$ & $34-71$ & $71-34$ & $34-29$ & $29-5$ & $5-0$ \\
\hline
\end{tabular}

a\% $\mathrm{N}_{2}, \mathrm{He}, \mathrm{O}_{2}$

mixtures on the day were measured with a Vandagraph Mixchek Portable Helium and Oxygen Analyser (St Ives, Cambridgeshire) and then entered into his personal dive computer $\left(\mathrm{HelO}_{2}\right.$, Suunto Oy, Vantaa, Finland) immediately before the dive. During the dive the diver followed the decompression information displayed by his personal dive computer, which recalculated the diver's decompression obligation in real-time. This was a stand-alone dive with no diving for at least the previous week and no previous dives accounted for in the dive planning. Planned and actual gas blend switches are presented in Table 1. The surface of the entry lake, reached by 400 stairs over an $80 \mathrm{~m}$ descent, was at an altitude of $195 \mathrm{~m}$. Altitude is known to affect both estimation of depth by the measurement of pressure by dive computers and also the physiological susceptibility to decompression sickness by divers (the higher the lake then the easier it is to suffer decompression sickness, due to the reduced ambient surface pressure). When decompression planning, in practice altitudes $<200 \mathrm{~m}$ are considered equivalent to sea-level. When climbing the stairs $2 \mathrm{~h}$ after the dive he became exhausted halfway, with dizziness and dyspnoea, and had to lie down, from where he was carried up to ground level on a trolley on rails normally reserved for dive equipment. He then experienced leg weakness, knee pain and was noted to have a "staggering gait". This was followed by bilateral leg muscle fatigue and knee pain which increased in both thighs until he received further oxygen breathing after which the pain changed character somewhat towards severe muscle soreness. He was evacuated by car to the nearest recompression facility where he arrived $3 \mathrm{~h}$ later. Apart from a slight difficulty with left sided finger-nose testing there were no focal neurological symptoms on arrival to the hospital. A diagnosis of chokes, DCS (and possibly in-part neurological DCS), was made and recompression to 2.8 ATA according to the United States Navy treatment table 6 commenced 6-7 h after surfacing, in a Sechrist 3200 monoplace chamber. About 15 min after pressurisation the patient experienced noticeable relief in symptoms. No extensions were added to the 5-h treatment. As the symptoms did not regress completely, within the next
$24 \mathrm{~h}$ he received two additional regular hyperbaric oxygen treatments at 2.8 ATA, each lasting $100 \mathrm{~min}$. The residual symptoms from knees and surrounding muscles gradually disappeared within 3 days and at $2 \frac{1}{2}$ years follow up he had made a full recovery and returned to diving.

Depths were recorded and planned for in $\mathrm{mfw}$ therefore each depth was divided by 1.03 to equate to pressure in msw for the estimation of tissue pressures using the $\mathrm{R}$ package SCUBA (ver. 1.7-0, A Baddeley, Perth Western Australia). Stepwise inert gas pressures in 17 Bühlmann compartments (ZH-L16A) were estimated from the profile recorded by the $\mathrm{HeIO}_{2}$ dive computer worn by the diver (max depth $110 \mathrm{mfw}$, total time $170 \mathrm{~min}$ ) [7, 8]. Both compartment 1 and its alternate $1 \mathrm{a}$ were included thus increasing the total number from 16 to 17 . Compartment 1 has a half-time of $4 \mathrm{~min}$ and $1 \mathrm{a}$ a halftime of $5 \mathrm{~min}$. While decompression planning software uses either one or the other, for the purpose of interrogating the profiles in this study both were included. Bühlmann compartments were selected because they are commonly used and there are more of them than in other popular Haldanian models. The RGBM dive plan generated a priori to the dive by the diver's desktop software (Dive Manager 4, Suunto Oy, Vantaa, Finland) with a personal setting of -2 was similarly interrogated (max depth $113 \mathrm{mfw}$, total time $145 \mathrm{~min}$ ), as was a third profile with reduced deep stops $(<1 \mathrm{~min}$ at $>48 \mathrm{~m},<2 \mathrm{~min}$ at $>30 \mathrm{~m}$, $<3$ min at $>21 \mathrm{~m}$ ) generated for comparison (V-Planner, HHS Software Corp., Kingston, ON, Canada) using the Varying Permeability Model (VPM) (max depth $113 \mathrm{mfw}$, total time 145 min) with conservatism set to +2 . The VPM-B/E variation was used because it is advertised as a variation of the VPM for “...the extreme or extra long dives and exposures" [9]. Furthermore, the manufacturer advises "It gives a more relaxed version of a profile for dives when extra safety is prudent" [9]. Both dive plans were matched to the actual dive in descent rate, arrival time at maximum depth, time ascent commenced and gases breathed (Fig. 2). The two plans were also matched on maximum depth and total dive time (Fig. 2), only the ascent profiles differed (the RGBM plan had longer deep stops). Bühlmann ZH-L16A $a$ and $b$ values 


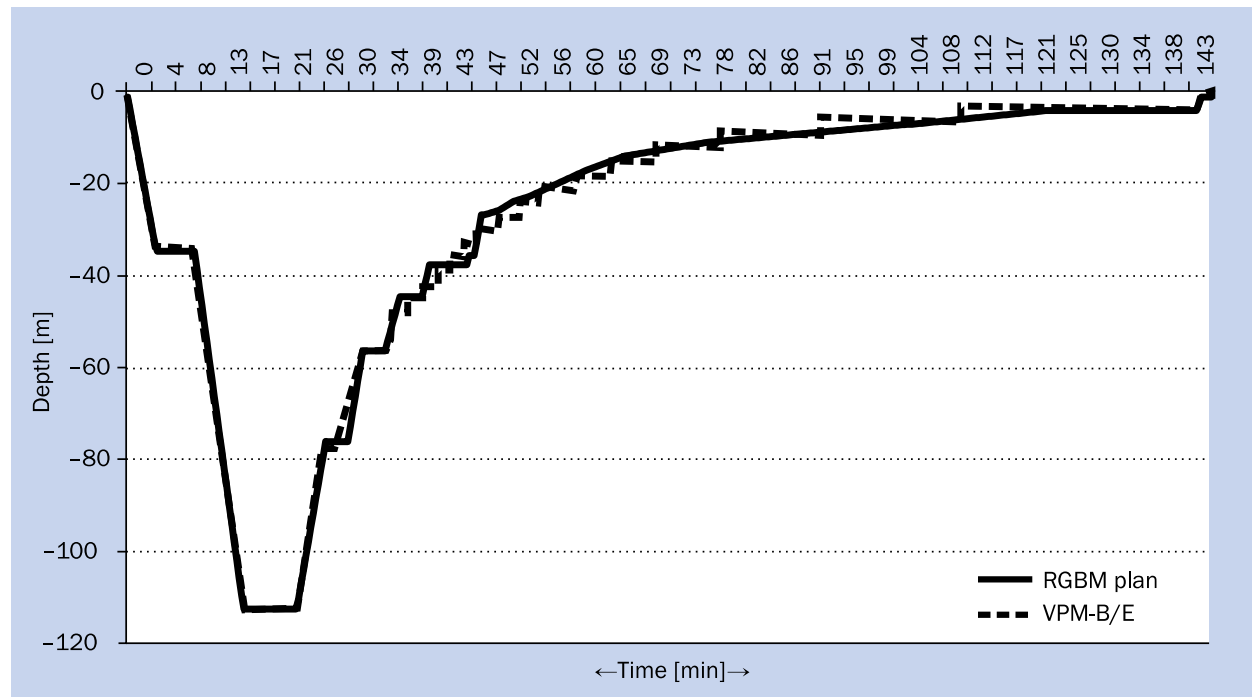

Figure 2. Planned dive profiles with deep stops (RGBM) and reduced deep stops (VPM-B/E)

were calculated for nitrogen and helium from published halftimes using equations 1 and 2 , where $T_{\text {half }}$ is the half-time in min for the respective compartment $[8,10,11]$ :

$$
\begin{aligned}
& a=2 T_{\text {half }}-1 / 3 \\
& b=1.005-T_{\text {half }}-1 / 2
\end{aligned}
$$

Intermediate combined inert gas $a$ and $b$ values for each compartment were calculated by linear interpolation of the values for nitrogen $\left(\mathrm{N}_{2}\right)$ and helium $(\mathrm{He})$ using equations 3 and 4 [12].

$$
\begin{aligned}
& a_{(\mathrm{He}+\mathrm{N} 2)}=\left(a_{\mathrm{He}} \cdot P_{\mathrm{He}}+a_{\mathrm{N} 2} \cdot P_{\mathrm{N} 2}\right) /\left(\mathrm{P}_{\mathrm{He}}+\mathrm{P}_{\mathrm{N} 2}\right) \\
& \mathrm{b}_{(\mathrm{He}+\mathrm{N} 2)}=\left(\mathrm{b}_{\mathrm{He}} \cdot \mathrm{P}_{\mathrm{He}}+\mathrm{b}_{\mathrm{N} 2} \cdot \mathrm{P}_{\mathrm{N} 2}\right) /\left(\mathrm{P}_{\mathrm{He}}+\mathrm{P}_{\mathrm{N} 2}\right)
\end{aligned}
$$

$\mathrm{P}_{\mathrm{He}}$ and $\mathrm{P}_{\mathrm{N} 2}$ are the dissolved partial pressures of $\mathrm{He}$ and $\mathrm{N}_{2}$ respectively. At any time during the dive minimum tolerable ambient pressure for each compartment, (and, therefore, maximum allowed ascent to the next decompression stop), was estimated using equation 5, hereafter referred to as " $\mathrm{P}_{\text {amb.tol }}$ "

$$
P_{\text {amb.tol }}=\left(P_{\text {comp.i }}-a\right) b
$$

where $P_{\text {comp.i }}$ is the inert gas pressure within compartment $i$. These pressures were divided by the respective ambient pressure at time (t) to give a percentage of the allowable pressure (according to the model) that each compartment was exposed to at each step. Maximum percentage of each $\mathrm{P}_{\text {amb.tol }}$ are presented for each compartment in Table 2 as are percentage of allowable surfacing pressures which are merely the percentage of $P_{\text {amb.tol }}$ but for depth $=0 \mathrm{~m}$ (intercept $\mathrm{M}_{0}$ of the $\mathrm{M}$-values) calculated using equations 6 and 7 .

$$
\begin{aligned}
& M_{0}=a+1 / b \\
& \% M_{0} \text { value }=100 \% *\left(p_{\text {surfacing }} / M_{0}\right)
\end{aligned}
$$

The maximum difference (tension) $\Delta \mathrm{P}$ between dissolved inert gas in each compartment and inspired inert gas are also presented in Table 2. The respective times when theoretical off-gassing tension peaked are noted in parentheses.

\section{RESULTS}

Planned and actual gas-switches (Table 1) suggest total inert gas partial pressures were as predicted by the plan until the diver reached the decompression stop in the $50^{\text {th }}$ min whereupon the depth was $29 \mathrm{mfw}$ instead of $21 \mathrm{mfw}$ and the actual blend of gas he switched to contained $61 \%$ inert gas (and 39\% oxygen) instead of the planned $50 \%$ inert gas and $50 \%$ oxygen. The diver breathed this higher-than-anticipated inert gas combination for the next $49 \mathrm{~min}$ until he reached $6 \mathrm{mfw}$ and switched to oxygen. Estimated resultant off-gassing peak inert gas differentials, maximum percentage $P_{\text {amb.tol }}$ during decompression and percentage $\mathrm{M}_{0}$ upon surfacing are presented in Table 2 .

Off-gassing is estimated to have peaked in each compartment at close to the planned times. Maximum $\Delta \mathrm{P}$ between dissolved and inspired inert gas was always estimated to have been lower in the actual dive than in either plan for compartments 1-11. Compared with the reduced deep stops plan the RGBM plan with deep stops would have produced higher maximum percentage of $P_{\text {amb.tol }}$ pressures in compartments $1 \mathrm{a}-9$, but lower values in compartments 10-14. At the end of the dive the estimated percentage of surfacing $M_{0}$ values for the actual dive were equal to, or lower than, those in either dive plan, likely due to the extended time decompressing on oxygen in the habitat.

\section{DISCUSSION}

The diver arrived at maximum depth one half-a-minute later than planned, reached only $110 \mathrm{mfw}$ instead of the planned $113 \mathrm{mfw}$ and then left the bottom $1 \mathrm{~min}$ 


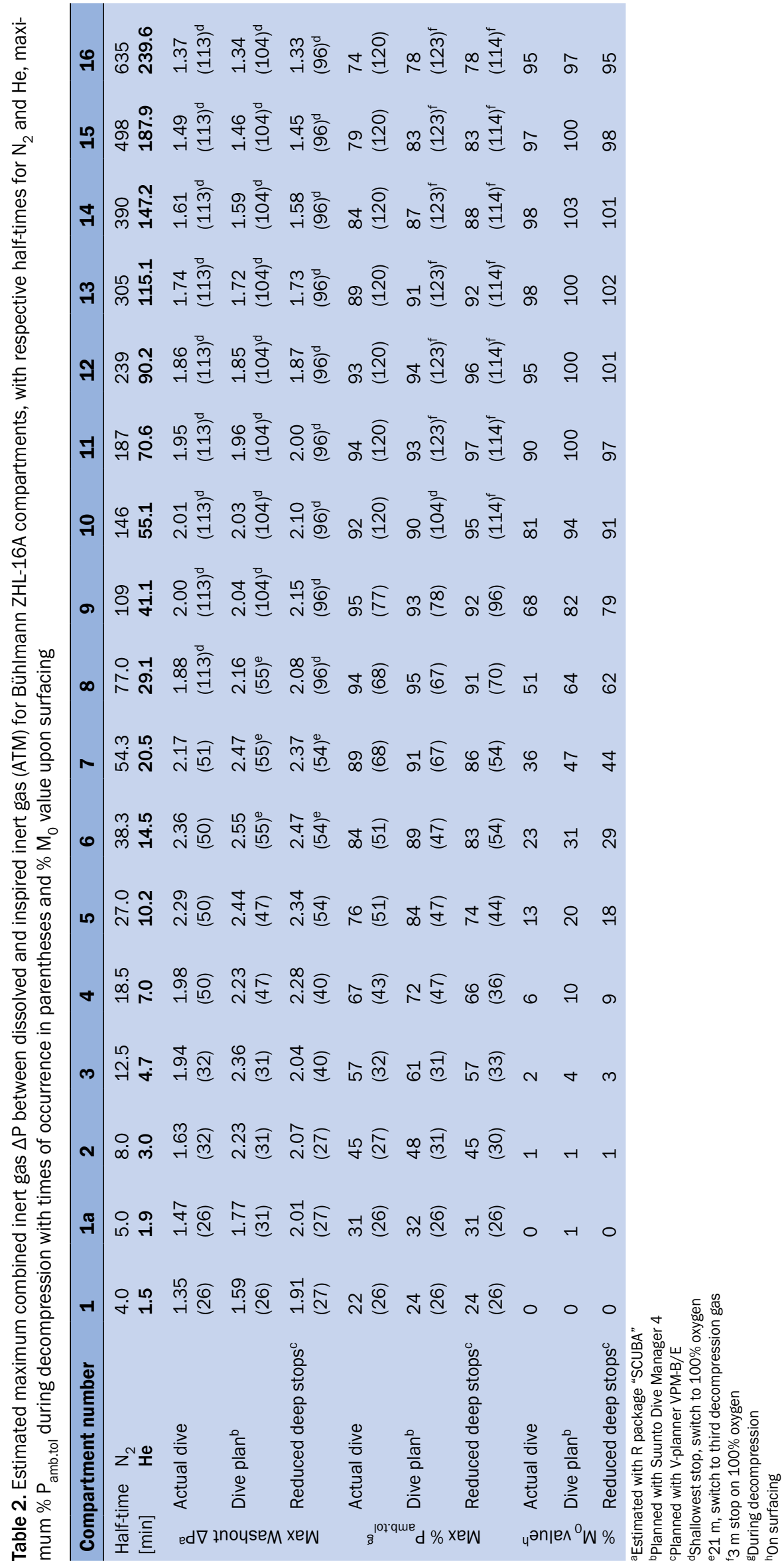


ahead of schedule. During the ascent these small but more conservative deviations from the plan allowed the diver to commence decompression at a less saturated state than planned. Maximum $\Delta \mathrm{P}$ (Table 2) was lower than planned, as was max\% $\mathrm{P}_{\text {amb.tol }}$, though $\% \mathrm{P}_{\text {amb.tol }}$ peaked in the 7 slowest compartments at 120 min just as the diver reported exerting himself climbing out of the water inside the habitat. This occurred after breathing 11\% more inert gas than had been planned for (Table 1) during the ascent from $21 \mathrm{mfw}$ to $6 \mathrm{mfw}$, (and switching to that gas $5 \mathrm{~min}$ ahead of schedule, at depth $29 \mathrm{mfw}$ ). It is possible that the diver's personal dive computer signalled that a gas-switch was desirable or permissible earlier than expected given the lower partial pressure of oxygen (0.38 ATA vs. 0.49 ATA; Table 1) but that is mere speculation at this time, long after the event. It appears as though the estimated surfacing M-values in the 8 fastest compartments were lower than planned for.

Concerns have been raised that during single-gas dives deep stops might reduce VGE at the expense of increased supersaturation in slower compartments $[2,4]$. In this analysis the maximum $\Delta \mathrm{P}$ between dissolved and inspired inert gas was higher in the fastest compartments (1 and 1a) for the reduced deep stops profile than for the plan with deep stops (1.91 and 2.01 ATA vs. 1.59 and 1.77 ATA, respectively) and lower in compartments 5-8 which, while not conclusive, is in keeping with this notion. In a 2007 review of deep decompression stops, Fock advised that decompression software-generated (VPM and RGBM) profiles utilising deep stops likely resulted in higher predicted inert gas tensions in the mid and slow compartments and that for dives greater than 70 msw these surfacing compartment tensions commonly exceed those shown experimentally to produce clinical symptoms [2]. Doolette echoed this concern but suggested that effective gas switching has the potential to ameliorate the shift [4]. In this study, using a simple exponential function to estimate inert gas uptake and washout over a range of compartment half-times, we concur that, when coupled with effective gas switching, deep stops did not in this case appear to shift decompression stress back towards slower compartments (when considering only the 3 parameters selected in this analysis). It nonetheless remains possible that estimates of other parameters associated with decompression stress may suggest a different effect upon decompression stress.

\section{LIMITATIONS OF THE STUDY}

The limitations of this report include that no physiological data were collected (gas consumption, thermal status, bubble detection, etc.). The exact cause of DCS in this case remains undetermined although climbing 200 stairs within $2 \mathrm{~h}$ of surfacing was likely not beneficial. Other factors may well have played a part, such as personal susceptibility (e.g. the ventricular septal defect), deviation from the planned profile and/or planned schedule of gases, etc., and our analysis neglects these to focus only on the potential effect of deep decompression stops upon inert gas supersaturation in various compartments. We do not intend to imply these are the sole cause of DCS. Deep-stop enabled trimix dive computers are widely available and more recreational technical divers than ever are diving deeper than 100 msw before conducting deep stops. While deep stops and bubble models remain to be validated with human data this issue urgently deserves further research to improve decompression safety following exceptional exposures. Until such formal validation is conducted we recommend all exceptional exposure dives planned with bubble models be considered experimental.

\section{CONCLUSIONS}

As an aside, we conducted the exact same analysis as for Table 2 except as though no gas switches had taken place and all dives (planned or actual) were completed on the starting gas, trimix 30/30. The data (not shown here) are available on request and we observed no difference in estimated surfacing supersaturation $\left(\mathrm{M}_{0}\right)$ in any compartment between the plan with deep stops and the plan with reduced deep stops but, compared with the reduced deep stops plan, we did find a shift in estimated greatest

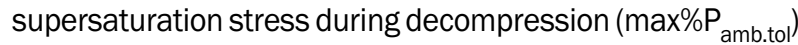
towards slower compartments in the plan with deep stops. Concerning dives with deep stops, a parameter potentially worth exploring further may not be so much the surfacing value as in the maximum decompression stress (supersaturation) during ascent. In this study we selected 3 parameters that are commonly referred to in diving supersaturation, namely tissue supersaturation pressure, percentage $P_{\text {amb.tol }}$ during the dive and percentage M-value at the end of the dive, but there are many more parameters that might be explored. Given this analysis is of a single case these three parameters were thought adequate but this remains a limitation.

\section{ACKNOWLEDGEMENTS}

We thank the diver for his informed consent to re-visit this experience. Peter Buzzacott and Virginie Papadopoulou participated in this project with the support of the PHYPODE Marie Curie Initial Training Networks (FP7-PEOPLE-2010-ITN). The recorded dive profile is now freely accessible within the SCUBA package [7].

\section{CONFLICT OF INTEREST}

In June 2012 Peter Buzzacott was unconditionally given a DG-05 dive computer by Hollis (San Leandro, CA, USA), a company that manufactures dive computers. 


\section{REFERENCES}

1. Mitchell SJ, Doolette DJ. Recreational technical diving part 1: an introduction to technical diving methods and activities. Diving Hyperb Med 2013; 43: 86-93.

2. Fock A. Deep decompression stops. Diving Hyperb Med 2007; 37: 125-132.

3. Wienke B. Diving decompression models and bubble metrics: modern computer syntheses. Comput Biol Med 2009; 39: 309-331.

4. Doolette DJ, Mitchell S. Recreational technical diving part 2: decompression from deep technical dives. Diving Hyperb Med 2013; 43: 96-104.

5. Gutvik CR, Mollerlokken A, Brubakk AO. Difference in bubble formation using deep stops is dependent on bottom time; experimental findings and theoretical support. 33rd Annual Scientific Meeting of the EUBS; Sharm El Shiekh, Egypt: European Undersea and Baromedical Society; 2007: p. 146-49.
6. Doolette DJ, Gerth WA, Gault KA. Redistribution of decompression stop time from shallow to deep stops increases incidence of decompression sickness in air decompression dives. Panama City, FL: Navy Experimental Diving Unit. 2011. Report No.: 11-06.

7. Baddeley A. The scuba package for the R system. Available at cran. r-project.org/web/packages/scuba; Perth, WA 2011.

8. BühImann AA. Tauchmedizin. Springer-Verlag, Berlin 1995.

9. The VPM-B model. HHS Software Corp.; [cited 2013 12th November]; Available from: http://www.hhssoftware.com/v-planner/ vpmdetail.html.

10. Powell M. Deco for Divers. Southend-on-Sea. ISBN 1-905492-07-3; 2008.

11. Schellart NAM, van Rees Vellinga TP, van Hulst RA. Body fat does not affect venous bubble formation after air dives of moderate severity: theory and experiment. J Appl Physiol 2013; 114: 602-610.

12. Baker EC. Understanding M-values. Immersed 1998; 3: 23-27. 